\title{
A matemática no encontro do velho e do novo mundo
}

\author{
Mathematics at old and new world encounter
}

Ubiratan D'Ambrosio ${ }^{1}$

\section{Resumo}

A partir do século XV as nações europeias intensificaram suas viagens marítimas, navegando por mares até então desconhecidos com os mais diversos objetivos. A maior motivação era abrir rotas comerciais para o Oriente, particularmente a Índia e a China, como alternativa às chamadas rotas da seda utilizadas desde a Antiguidade. No caminho foram encontrando terras, com recursos naturais importantes, e povos desconhecidos. Em nome dos monarcas patrocinadores das viagens, tomaram posse das novas terras. É o início da Era das conquistas e do Colonialismo.

Palavras-chave: navegações; conquistas; sistemas de conhecimento.

\section{Abstract}

From the 15th century European nations have intensified their maritime journeys, sailing through hitherto unknown seas with the most diverse goals. The main motivation was opening trade routes to the East, particularly India and China, as an alternative to the socalled silk routes used since Antiquity. On the way they were finding lands with important natural resources, and unknown peoples. On behalf of the monarchs sponsoring the voyages, they took possession of the new lands. It is the beginning of the Era of Conquest and Colonialism.

Keywords: navigation; conquest; knowledge systems.

\footnotetext{
${ }^{1}$ Universidade de São Paulo | ubi@usp.br
} 
Jamais usam pesos e medidas, nem têm números por onde contem mais que até cinco, e, se a conta houver de passar daí, a fazem pelos dedos das mãos e pés. Frei Vicente do Salvador, 1627

\section{As navegações}

A história da navegação como a arte de direcionar navios sobre o mar aberto nos mostra práticas tradicionais, muita astronomia e geometria. Está presente desde a préhistória. As navegações sempre foram dependentes de uma combinação de habilidades, do desempenho das naus, isto é, de tecnologia, e de condições meteorológicas. Os objetivos das navegações eram os mais variados. Viajando aos limites do mundo conhecido, procuravam confirmar narrativas mitológicas e lendárias sobre lugares e pessoas fabulosas. Logo depois os objetivos incluíram satisfação de interesses materiais, como saqueios e pilhagens, trocas e pactos comerciais. As navegações ajudaram a construir o conhecimento científico, particularmente astronômico e matemático, a tecer a organização das várias sociedades e a estabelecer grupos de poder, como as monarquias e impérios.

Há evidência de alguma forma de navegação desde a Idade da Pedra, cerca de 150.000 anos atrás. Os barcos mais antigos encontrados são canoas e troncos de madeira escavados na Holanda, de cerca de 9.000 anos atrás.

A partir de embarcações primitivas, tipo balsas e canoas, já a partir do $3^{\circ}$ milênio a.C. se desenvolveram os primeiros navios no Pacífico, nas ilhas da Polinésia, no Oceano Índico e no Mediterrâneo, sobretudo com os Fenícios, os Cartaginese, Grécia e Roma. A força motriz das embarcações era remar, geralmente função de escravos. Há evidência de serem utilizadas, no período helenístico e romano, velas para captar a energia dos ventos. Também se nota isso na África Ocidental em 1311, quando Abubakari II, Imperador do Mali, o maior império do mundo na época, partiu da costa de Gâmbia, com 2.000 barcos de remo e velas em uma expedição ao desconhecido, ao Oceano Atlântico tentando atingir a outra margem do grande rio. Jamais retornou. Teria chegado à outra margem? Há indícios de contatos anteriores entre a África e as Américas. (SERTIMA, 1976) Há grande controvérsia entre historiadores. (WELDSHMAN, 2002, 2003)

Com a emergência do Islão, as navegaç̃̃es se estenderam. A expansão do islamismo levou a navegar não só pelo Mediterrâneo, mas também pelo Golfo Pérsico, pelo Oceano Índico e pelo Pacífico. Isso exigia não só naus mais poderosas, mas também técnicas e instrumentos de navegação muito sofisticados, tais como bússola magnética, um instrumento rudimentar conhecido como kamal e o quadrante. Também eram usados mapas, sobretudo costeiros e impregnados de concepções mitológicas. Os muçulmanos desenvolveram como força motriz para suas embarcações a energia eólica, utilizando velas triangulares, as chamadas velas latinas. Construíram grandes navios mercantes de três mastros para o Mediterrâneo, como o qarib e o carraca, usados pelos navegadores de alAndaluz no século XIII, com uma capacidade de 200 a 600 toneladas. Deram origem aos galeões, que foram adotados em toda a Europa. Também deram origem ao navio caravela, naus pequenas, muito rápidas e com grande capacidade de manobrabilidade, que foram desenvolvidas pelos portugueses para viagens de longa distância, a partir do século XV e mais tarde adotados por outros países. 
Com a emergência do Islão, o ramo Omaiada dos muçulmanos se dirigiram para o Leste e invadiram e Península Ibéria em 711, chamando a região conquistada de al-Andaluz. Em 756 estabeleceram sua capital na cidade de Córdoba. A cidade tornou-se um grande centro intelectual, com tolerância para judeus e cristãos. Mas imediatamente após a conquista da Península Ibérica, os reinos cristãos iniciaram um processo de reconquista. Lisboa foi reconquistada em 1147 por Dom Afonso Enriques (1110-1185), fundando o Reino de Portugal, que foi mais tarde consolidado por D. Dinis (1229-1325). Para o novo reino, cercado de nações hostis, foi necessário buscar recursos alimentares e parcerias comerciais pelo mar. Assim se intensificam as relações com a Inglaterra e a navegação pelo Atlântico Norte, sobretudo para pesca, e a busca de rotas costeiras para o Sul. A navegação tornouse prioridade do Reino de Portugal. Reconhecendo a importância das navegações, o Rei Dom João I (1257-1433) encarregou seu filho, o Infante Dom Henrique (1394-1460), herói da conquista de Ceuta, no Marrocos em 1415, a coordenar o grande projeto de Navegações Marítimas. Dom Henrique, cognominado O Navegador, reunia em sua residência, em Sagres, importantes cartógrafos, cientistas e navegadores de toda a Europa.

A Índia e a China eram as fontes dos produtos mais cobiçados pelos comerciantes de toda a Europa, dentre esses seda e especiarias. Só eram atingidas por vias terrestres, que eram inacessíveis a Portugal. Surgiu então um grande projeto marítimo: contornar a África para chegar à Índia e daí à China. O Rei Dom João II (1455-1495) assumiu esse projeto. Como parte desse projeto foi desenvolvida uma nau pequena, barcos leves e velozes, fortemente armados e facilmente manobráveis. Essa nau era a caravela, chamada por outros países como o "homem de guerra português".

Em andamento do projeto, Lopes Gonçalves cruzou o Equador em Cabo Lopez (atual Gabão) em 1473. Prosseguindo para o Sul, o obstáculo era o Cabo das Tormentas (na atual África do Sul). Em 1488, Bartolomeu Dias (1450-1500) cruzou o Cabo das Tormentas, rebatizando-o como Cabo da Boa Esperança. Cruzar o cabo foi decisivo para o navegador Vasco da Gama (ca. 1469-1524) aportar em Calicut, Índia, em 1498. Chegava assim, com êxito, o projeto de Portugal para atingir a Índia.

Em 1492, pouco antes de completar este projeto, um navegador genovês, Cristóvão Colombo (1451-1506), radicado em Portugal desde 1475 e integrante da equipe de navegadores oficiais, com base nas cartografias de Fra Mauro, de Beahim e de outros, propôs ao Rei Dom João II viajar pelo Oceano Atlântico, somente no Hemisfério Norte, chegando ao Japão, que havia sido descrito por Marco Polo, e daí chegar à China e às Índias. O projeto fazia sentido, mas os recursos financeiros de Portugal não permitiram dar andamento a esse projeto. Na impossibilidade de financiar esse novo projeto, o Rei Dom João II encaminhou Cristóvão Colombo aos Reis da Espanha, Fernando de Aragão (14321516) e Isabel de Castela (1451-1504). Nesse mesmo ano, 1492, haviam derrotado o califa Boabdil, em Granada, assim finalizando a Reconquista integral da Península Ibérica.

Também a Espanha necessitava rotas marítimas para o Oriente. Os chamados Reis Católicos também tinham interesse nas navegações para chegar às Índias e acolheram Cristóvão Colombo na corte para levar adiante seu projeto. Mas o Projeto de Cristóvão Colombo era muito caro e foi necessário aos Reis Católicos recorrerem a empréstimo do Banco dos Médici, que já havia se instalado na Espanha. Um dos gerentes do banco era Amerigo Vespucci (1454-1512), que se encarregou de acompanhar o projeto financiado pelo banco. 
Em 1492 Cristóvão Colombo partiu, com três navios Santa Maria, Pinta e Nina, e em 12 de outubro atingiu terra, prenúncio de atingir seu destino, onde desembarcou. Voltou e relatou aos Reis que havia alcançado ilhas próximas a Chipango (Japão), entrada para a Índia, chamando essas ilhas de Índias Ocidentais. Jamais soube que era um outro continente, que seria depois chamado Américas.

Havendo evidência de mais terras para o Oeste, Portugal e Espanha decidiram estabelecer, sob legalização papal, uma divisão das novas terras descobertas e a serem descobertas. Assim nasceu o Tratado de Tordesilhas, firmado em 1493/1494, dividindo o mundo entre Portugal e Espanha. Para Portugal só interessavam as terras ao Leste (África e Índias Orientais), ficando para a Espanha as do Oeste, as Índias Ocidentais.

Como consequência do grande sucesso das viagens de Cristóvão Colombo (1451-1506) pelo hemisfério norte, chegando à América em 1492, e de Vasco da Gama (ca.1469-1524) aportando na Índia em 1498 pelo hemisfério sul, seguem-se outras viagens. Em 1500, Pedro Álvares Cabral (1467?-1520?), comandando uma frota que se dirigia à India, aportou no Brasil. Em 1501 e 1502, Amerigo Vespucci (1454-1512), que havia acompanhado Colombo em algumas de suas viagens, foi contratado por Dom Manuel I, o Venturoso, Rei de Portugal, para reconhecer as terras do Atlântico Sul, que Cabral havia encontrado. Vespucci percorreu a costa brasileira desde o Cabo de São Roque, RN até o Rio da Prata, implantando em cada parada o marco de pedra com o brasão do rei de Portugal, que significava a posse da terra. Em 1520, Fernão de Magalhães (c.1480-1521), viajando a serviço de Carlos I (1500-1555), Rei da Espanha, encontrou a passagem marítima para o Pacífico no Sul do novo continente, conhecido hoje como Estreito de Magalhães, no extremo sul da América do Sul. Assim, em 28 anos, de 1492 a 1520, o planeta se globalizou. A descoberta de novas terras despertou interesse geral na Europa e seguiram-se inúmeras viagens de navegantes, sobretudo ingleses, franceses e holandeses.

A grande proeza de viajar por todos os mares descobrindo novas terras, novos povos e novas possibilidades foi resultado de um projeto de grande envergadura que se originou nos primeiros tempos da monarquia portuguesa, como foi discutido acima. O mais importante cronista da época é Duarte Pacheco Pereira (c.1460-1533). Na sua obra monumental, o Esmeraldo de Situs Orbis, ele fala sobre o conhecimento nos descobrimentos e faz um importante relato sobre o que se sabia e o que se aprendeu no encontro com novos povos e novas culturas, notadamente referindo-se à África.

\section{Que conhecimentos possuíam os navegantes ibéricos e das demais nações?}

As navegações dependiam fundamentalmente de como, intencionalmente ou por acaso, os navegantes chegavam ao descobrimento de novos povos e novas culturas. As navegações dependiam muito de conhecimentos matemáticos, particularmente astronômicos e geométricos. O conhecimento matemático na época era muito diferente do que hoje entendemos por matemática.

A partir das Cruzadas, quando se inicia a Baixa Idade Média e na entrada no Renascimento, pode-se distinguir quatro tipos de matemática sendo praticados nas nações europeias: 
- matemática abstrata, teórica, ligada a fenômenos naturais e questões místicas e religiosas - Tomás de Aquino (ca. 1225-1274), Thomas Bradwardine (?1290-1349), Nicolau Copérnico (1473-1543);

- matemática mercantil, contábil, comercial, diletante - Luca Pacioli (1445?-1514), Bastiano da Pisa, il Bevilacqua (1483?-1553), Nicoló Tartaglia (1500?-1557), Gerolamo Cardano (1501-1576);

- matemática de arquitetos e artistas - Sebastiano Serlio (1475-1554), Albrecht Dürer (1471-1528);

- matemática das navegações, astronomia, geografia e geometria - Pedro Nunes (1502-1572).

Cada um desses tipos tinha um estilo próprio, com objetivos e métodos muito específicos. Os nomes citados são representativos de cada um desses estilos. Suas biografias e bibliografias servem de apoio para a diferenciação que proponho entre os tipos de matemática praticados na época. As relações entre essas diferentes matemáticas eram raras até meados do século XVI. Embora meu objetivo aqui não seja analisar essas diferentes matemáticas e suas relações, algumas características de cada uma delas podem ser notadas no curso deste trabalho.

É importante destacar que esses quatro tipos são ramificações de um pensar que remonta a espécies anteriores ao homo sapiens e que respondem a dois grandes pulsões que caracterizam as espécies humanas, a sobrevivência e a transcendência.

$\mathrm{Na}$ busca da sobrevivência desenvolveram-se meios de lidar com o ambiente mais imediato, que fornece o ar, a água, os alimentos, o outro, e tudo o que é necessário para a sobrevivência do indivíduo e da espécie. São estilos de comportamento individual e coletivo e técnicas primitivas.

Na busca da transcendência desenvolveram-se a percepção de passado, presente e futuro e os meios para explicar seu encadeamento e fatos e fenômenos naturais e sociais. Esses meios são a memória, individual e coletiva, e os mitos, que se organizam como tradições e história, o que inclui religiões e sistemas de valores. Como será o futuro é um questionamento permanente. Para "conhecer" o futuro desenvolveram-se artes divinatórias baseadas em sistemas de explicações, impregnadas de mitos. Exemplos de artes divinatórias são a astrologia, os oráculos, o / Ching, a numerologia e, em geral, as ciências e as matemáticas, através das quais procura-se antecipar o que pode acontecer. Analisando a geração, a organização intelectual e social e a transmissão e difusão dessas categorias (comportamento individual e coletivo, técnicas, história, tradições, religiões, sistemas de valores, sistemas de explicações, artes divinatórias) pode-se entender o conhecimento. Em particular, o conhecimento matemático.

\section{Uma síntese da História da Matemática até a Idade Média.}

Vou fazer uma revisão muito rápida de como se desenvolveu o conhecimento matemático na Bacia do Mediterrâneo. Começo examinando os tempos de Grécia e Roma. O conhecimento matemático desenvolvido pelos gregos absorveu o que era conhecido pelos demais povos do Mediterrâneo, incorporou o imaginário grego e foi absorvido por eles, com características diferentes. Ao assimilar o conhecimento matemático eminentemente prático dos egípcios e dos babilônicos, os gregos criaram uma matemática 
abstrata, teórica e dedutiva. São óbvias as características místicas e religiosas dessa matemática, que veio preencher um vazio não resolvido pela rica mitologia grega. Na verdade, essa matemática caracterizou a civilização grega. Os ideais de beleza, o rigor e as dúvidas filosóficas, a organização social e política e mesmo as práticas médicas guardam íntima relação com a matemática. Filosofia grega e matemática grega são, essencialmente, o mesmo modo de pensar, cultivado nas academias. ${ }^{2}$ Os povos subordinados ao Império de Alexandre, no século III a.C., estavam totalmente integrados nessa civilização.

O Império Romano, que se expandia pelo leste europeu, possuía uma matemática eminentemente prática, sem as características daquela desenvolvida pelos gregos, e nem mesmo pelos egípcios e babilônicos. Os sistemas de contagem e as medidas satisfaziam as necessidades do dia-a-dia, da urbanização e da arquitetura romanas. Por mais sofisticada que fosse a organização da sua sociedade e, portanto, os sistemas que permitiam sua operacionalidade, os romanos jamais se apropriaram integralmente do elaborado sistema filosófico do mundo grego.

Quando o Império Romano conquistou os territórios dominados pelos gregos, não houve restrições à continuidade do pensamento filosófico e matemático. As academias foram mantidas e estimuladas. Mas Roma absorveu somente o conhecimento matemático que interessava ao seu projeto imperial, aproveitando unicamente os aspectos práticos dessa matemática. Isso fica evidente no livro de arquitetura de Vitrúvio, que é a melhor síntese dos conhecimentos técnico-científicos dos romanos. (VITRUVIO, 1999) ${ }^{3}$ Não obstante o papel não essencial do pensamento grego entre a intelectualidade romana, floresceram importantes escolas matemáticas no Império Romano, com nomes como Ptolomeu e Diofante. A península ibérica, que era parte do mundo romano, também absorveu essa ciência prática.

Com o advento do cristianismo, a filosofia e a matemática gregas foram simplesmente deixadas de lado e mesmo rejeitadas, jamais penetrando nos mosteiros, que eram o espaço da intelectualidade cristã. ${ }^{4}$ Algumas poucas traduções não tiveram repercussão. Aos poucos, a própria língua grega caiu em desuso.

Nos primeiros séculos do cristianismo, a chamada Alta Idade Média, continuou-se a desenvolver conhecimentos científicos, filosóficos e matemáticos eminentemente práticos. A contagem se fazia com ábacos e dedos e os registros numéricos com o sistema de numeração romana. Isso era praticado na península ibérica. Uma importante fonte que temos sobre essa época é a obra de Santo Isidoro (ca 560-636), de Sevilha, que escreveu Etimologias, uma síntese do conhecimento da época, num estilo enciclopédico.

Deve-se notar que na região que poderíamos denominar periferia oriental do Império Romano, instalou-se, em 395, o Império Bizantino, capital Constantinopla, com forte influência grega e diferenças fundamentais do cristianismo de Roma. Essas diferenças culminaram com o grande cisma de 1054, que marcou a recusa dos cristãos bizantinos de

\footnotetext{
${ }^{2}$ De hekás longe distante + dêmos $\approx$ povo, segundo Junito Brandão: Dicionário Mítico-Etimológico, Vozes, Petrópolis, 1991.

${ }^{3}$ Um bom estudo sobre Vitrúvio e a matemática romana está no livro de Rubens G. Lintz: História da Matemática Volume 1, Editora da FURB, Blumenau, 1999.

${ }^{4}$ De monachós $\approx$ solitário, segundo Antônio Geraldo da Cunha: Dicionário Etimológico, Nova Fronteira, Rio de Janeiro, 1982.
} 
aceitarem a autoridade suprema do bispo de Roma, chamado Papa, sobre todos os cristãos. Surgiu assim a Igreja Ortodoxa.

A presença cultural grega continuava forte no Norte da África. Nessa região, a conversão ao cristianismo foi menos intensa e as tradições judaicas se mantiveram presentes. As tribos árabes, habitantes dessa região, foram unificadas a partir da revelação corânica, pela qual Maomé fundou, em 622, o Islamismo. O Corão, livro sagrado da nova religião, que se fundamenta nas mesmas tradições bíblicas dos judeus e dos cristãos, orientou a rápida expansão do islamismo. O Império Romano, já assolado pelos povos bárbaros do Norte da Europa, particularmente vikings e godos, foi desafiado pelo novo império que se organizava ao sul do Mediterrâneo.

Num rápido processo de conquista, o islamismo estendeu-se a toda a periferia do Império Romano e atingiu a península ibérica, pretendendo chegar a Roma. Em 732, eles foram detidos, em Poitou, por Carlos Martelo, reconhecido como o salvador da cristandade latina. O Islamismo instalou-se, porém, em praticamente toda a península ibérica. No Oeste, a capital do Império Bizantino, Constantinopla, hoje Istambul, resistiu as invasões islâmicas. Somente veio a ser conquistada, pelos turcos, em 1453.

A forte tradição cultural dos povos árabes foi um importante elemento no sucesso das conquistas islâmicas e no desenvolvimento de uma civilização que absorveu muito da cultura grega. Seguiu-se no Islamismo um grande desenvolvimento científico. Em 813, Abu al-Abbas al-Mamum (786-833) tornou-se Califa do Império Abássida, uma das divisões que resultaram do império islâmico após a morte de Maomé. Al-Mamum destacou-se por seu grande apoio à cultura científica e à monumental biblioteca denominada "Casa da Sabedoria", que seu pai Harun al-Rashid havia fundado em Bagdá. Ali estimulou um grande desenvolvimento para a ciência, a filosofia e a matemática herdada dos gregos. É interessante notar que sob al-Mamun foi elaborado o Livro do Tesouro de Alexandre, prontuário de saberes mágicos, alquímicos e farmacológicos, com fórmulas de elixires e venenos. (ALFONSO-GOLDFARB, 1999) Nos preceitos há uma precisão numérica das dosagens. A fundamentação teórica recorre a propriedades de triângulos e hexágonos, um importante exemplo de geometria mística, e que evidencia a presença da astrologia nessa cultura.

Fazia-se necessária uma astronomia que servisse de suporte a essa astrologia e também voltada à satisfação dos preceitos do Corão, como por exemplo orar em determinadas horas e direcionados para Meca, a sede sagrada do Islamismo. ${ }^{5}$ Havia também a necessidade de desenvolver uma nova prática econômica e financeira, sobretudo para seguir preceitos de propriedade e heranças estabelecidos no Corão. Havia necessidade de novas práticas matemáticas, com habilidades de cálculo que não faziam parte da matemática apreendida dos gregos e dos romanos. Foi necessário recorrer a conhecimentos matemáticos de outras culturas.

Muito desenvolvida era a matemática indiana, absorvida pelos Persas. Particularmente um sistema de numeração baseado em 10 símbolos, técnicas de operação e resolução de equações. Al-Mamun decidiu estimular a pesquisa matemática na Casa da Sabedoria e contratou um jovem matemático de Kwarizmi, no atual Uzbequistão, Abu Abdallah

\footnotetext{
${ }^{5}$ Muito curiosa a referência a esse rigor de horário na obra de José Saramago: História do Cerco de Lisboa, São Paulo: Companhia das Letras, 1989.
} 
Muhammad ibn Musa al-Kwarizmi (ca 780-ca 850). Além de importantes tabelas astronômicas, ele introduziu os algarismos, hoje denominados indo-arábicos, e os algoritmos das operações com esses algarismos. Também as operações básicas para a resolução de equações, que são a redução de termos semelhantes [al-muqabola] e transposição do sinal de igual com mudança de sinal [al-jabr], e a fórmula de resolução das equações de $2^{\circ}$ grau.

Enquanto prosperava o império islâmico, a Europa experimentava um período de consolidação do regime feudal e de intensificação do comércio. A necessidade religiosa de acesso aos locais sagrados do cristianismo, aliada à necessidade de novas rotas para abastecer um comércio emergente na próspera Europa medieval, deram origem a expedições de reconquista, que foram denominadas Cruzadas.

A partir da primeira cruzada, em 1096, a Europa cristã teve acesso aos elementos básicos da cultura árabe, inclusive interpretações da filosofia grega clássica. Iniciou-se, assim, uma revitalização das pesquisas nos mosteiros da Europa. Foi necessário criar um outro espaço intelectual, onde temas apreendidos dos hereges muçulmanos poderiam ser discutidos. Surgem assim as universidades, das quais as primeiras são em Bolonha (ca 1088) e Paris (ca 1170). Além disso, foi da maior importância a publicação, por Leonardo Fibonacci, de Pisa (c.1179-1240), do Liber abaci, tratando da numeração indo-arábica, das operações e da tabuada, e do Liber Quadratorum, ensinando a resolver equações quadráticas. Foram obras decisivas na renovação do conhecimento matemático e no suporte ao comércio e sistema financeiro emergentes.

Conhecia-se a aritmética como aparecia no livro de Euclides, como parte do quadrivium, mas que se referia a propriedades dos números, algumas místicas, e as relações entre números, presentes nos estudos sobre música e harmonia. A geometria de Euclides, focalizando as propriedades das figuras geométricas, despertava menor interesse, mas os movimentos de astros celestes, a astronomia, eram atrativos e importantes. O quadrivium, considerado o currículo superior de estudos, que se seguia ao currículo elementar, básico, o trivium (gramática+retórica+dialética) era composta por aritmética, música ( $\approx$ números em relação), geometria, astronomia ( $\approx$ formas em movimento). Essas sete disciplinas, organizadas em dois ciclos, constituíam a formação integral da intelectualidade europeia, desde a Antiguidade até a Idade Média.

Note-se que a síntese de conhecimentos absorvidos dos árabes após as cruzadas, com estilos e objetivos distintos e representando várias tradições, confluiu principalmente para os mosteiros. As preocupações tradicionais da filosofia, procurando explicar fenômenos tão presentes quanto o movimento, confundia-se com a teologia. O pensamento da Idade Média culmina com a obra maior que é a Summa Theologica, de São Tomás de Aquino. Essa síntese de conhecimentos sugeria que essas questões integrariam um mesmo corpo de ideias, que passou a ser conhecida por uma palavra ainda um tanto indefinida, matemática. Estavam assim sendo preparadas as bases para o surgimento de uma ciência que viria a ser identificada como Matemática e que, somente a partir do século XVIII viria a se estabelecer como uma ciência autônoma.

A maior influência para a modernização da matemática veio de Aristóteles. As reflexões sobre movimento, o fenômeno natural que mais intrigava os filósofos da época, eram intensas. Estudavam-se as relações entre espaço e tempo e a aceleração. Também havia uma preocupação com ótica. O trabalho dos monges-cientistas, principalmente na Inglaterra, dentre os quais se destacam Roger Bacon (ca 1214-1292?), Thomas Bradwardine 
(1290?-1349) e Guilherme de Ockham (1285-1349), foi fundamental como preparação para o surgimento da mecânica newtoniana.

A influência das reflexões, equivocadas, de Aristóteles foi fundamental no desenvolvimento da matemática. Sua afirmação que quanto mais pesado o corpo, maior sua velocidade de queda, passou por contestações. São importantíssimos os estudos de Thomas Bradwardine e de seus colegas no Merton College (William Heytesbury, Richard Swineshead, John Dumbleton et al).

Os quatro tipos de matemática que distingo na Baixa Idade Média e no Renascimento são o resultado da evolução, ao longo de muitos séculos, dessas categorias na região mediterrânea, evolução essa que se expandiu para a Europa central. Obviamente, tais categorias estão intimamente ligadas. Não podemos desvincular, por exemplo, o desenvolvimento da agricultura da religião e dos estudos meteorológicos e astronômicos que estão na base do desenvolvimento da matemática. Os quatro tipos de matemática distinguidos acima, mostrando estilos e cultores aparentemente desvinculados, são a resposta a um tipo de sociedade que se estabeleceu na época. Com a gradativa e maior complexidade com que foi se transformando a sociedade, esses tipos foram se mesclando.

Sob essa visão, não se pode tentar uma comparação em geral entre tipos de matemática praticada pelos conquistadores e pelos povos conquistados.

As categorias de análise (comportamento individual e coletivo, técnicas, história, tradições, religiões, sistemas de valores, sistemas de explicações, artes divinatórias) são presentes em todos os povos, mas completamente distintas. Portanto o conhecimento matemático que daí resulta será diferente para diferentes ambientes naturais e socioculturais. Qualquer tentativa de comparação será frustrante. O conceito de Etnomatemática evidencia isso.

O conhecimento matemático é o conjunto de técnicas, habilidades, maneiras [ticas] de explicar, de entender, de lidar [matema] com o ambiente cultural e natural [etno], desenvolvidas pelo homem em sua busca de sobrevivência e de transcendência.

Daí falarmos em etno-matema-tica.

Os conquistadores e colonizadores trouxeram a sua etnomatemática, gerada em torno do Mediterrâneo, a partir de tempos pré-históricos, para explicar, entender, lidar com fatos e fenômenos naturais dessa região. Essa etnomatemática mediterrânea foi desenvolvida por egípcios, babilônios, gregos, romanos, árabes e organizada na Baixa Idade Média e no Renascimento e foi difundida e assimilada por toda a Europa. Passou a ser denominada, simplesmente, Matemática.

Com essa matemática os europeus criaram um poderoso instrumento de investigação de fatos e fenômenos (ciência) e um instrumental para seu controle e expansão (tecnologia). Particularmente responsável por importantes inovações tecnológicas para navegar em mares desconhecidos, com maior intensidade na península ibérica, em especial em Portugal.

\section{O encontro cultural do Novo Mundo.}

Os comandantes das expedições e alguns membros da tripulação tinham um bom nível, alguns com formação universitária. Lembremos que Martim Afonso de Souza, que foi o fundador, em 1532, de São Vicente, a primeira cidade brasileira, tinha importantes credenciais acadêmicas, tendo sido aluno do grande matemático Pedro Nunes (1502-1578). 
Obras como as crônicas de viagens de Cristóvão Colombo e de Vasco da Gama e relatos de tripulantes são importantes fontes de informação sobre os conhecimentos náuticos da época e sobre o que viram nas novas terras.

Três documentos relatando o descobrimento do Brasil foram escritos por Pero Vaz de Caminha, pelo mestre João Faras e por um piloto anônimo. Quem é esse piloto anônimo? Essa carta/relação faz parte de uma coleção de textos publicados em 1507 pelo cartógrafo italiano Fracanzano da Montalboddo e depois republicado várias vezes, mas sempre sem qualquer referência sobre quem é esse piloto anônimo que acompanhou Cabral em toda sua viagem. Provavelmente um italiano, o que mostra o caráter internacional das navegações.

Nos três documentos, os autores falam dos tipos humanos e de alguns de seus costumes e da natureza. Por exemplo, o piloto anônimo diz:

De aspecto, esta gente são homens pardos, e andam nus sem vergonha e os seus cabelos são compridos. E têm a barba pelada. E as pálpebras dos olhos e por cima delas eram pintadas com figuras de cores brancas e pretas e azuis e vermelhas. Têm o lábio da boca, isto é, o de baixo, furado, e nos buracos metem um osso grande como um prego. E outros trazem uma pedra azul e verde e comprida dependurada dos ditos buracos. As mulheres andam do mesmo modo sem vergonha e são belas de corpo, os cabelos compridos. E as suas casas são de madeira coberta de folhas e de ramos de árvores com muitas colunas de madeira. No meio das ditas casas e das ditas colunas para a parede põem uma rede de algodão dependurada em que fica um homem e entre uma rede e outra fazem uma fogueira, de modo que numa só casa estão 40 ou 50 camas armadas à maneira de tear.

Os outros dois documentos da viagem de Cabral coincidem nessas observações. Os documentos dão uma pequena indicação de sua tecnologia, para a construção de habitações e o tipo de vida comunitária. Mas nenhum dos três relatos mencionam qualquer coisa que poderia sugerir conhecimento, religião e matemática. Na verdade, deve-se atribuir isso a não reconhecer especificidades de formas de conhecimento de outras culturas. Somente mais tarde, cronistas viriam a comentar sobre a religiosidade, a linguagem e a matemática dos indígenas.

Segundo relata Nicolas Barré, em 1556, o conhecimento numérico dos nativos era limitado. "Sua linguagem é bastante copiosa em expressões, mas sem números, tanto que quando querem significar cinco, eles mostram os cinco dedos da mão".

Uma outra referência sugere contagem de números maiores, associada ao tempo. Conforme relata Binot Paulmier de Gonneville, em 1504: "Arosca consentiu que seu jovem filho (...) viesse para a cristandade, porque prometiam ao pai e ao filho trazê-lo de volta dentro de 20 luas o mais tardar; pois assim significam eles os meses".

Uma explicação para a ausência de um sistema de numeração reconhecido como tal é dada por frei Vicente do Salvador (1564?-1636?) na primeira história do Brasil, completada em 1627:

Pois hei tratado neste capítulo do contato matrimonial deste gentio, tratarei também dos mais contratos, e não serei por isso prolixo ao leitor, porque os livros que hão escrito os doutores de Contractibus sem os poderem de todo resolver, pelo muito que de novo inventa cada dia a 
cobiça humana, não tocam a este gentio; o qual só usa de uma simples comutação de uma coisa por outra, sem tratarem do excesso ou defeito do valor, e assim com um pintainho se hão por pagos de uma galinha. Nem jamais usam pesos e medidas, nem têm números por onde contem mais que até cinco, e, se a conta houver de passar daí, a fazem pelos dedos das mãos e pés. O que lhes nasce de sua pouca cobiça; posto que com isso está serem mui apetitosos de qualquer coisa que vêem, mas, tanto que a têm, tornam facilmente de graça ou por pouco mais que nada. (SALVADOR, 1965, pp. 89-90).

São muito importantes as crônicas das conquistas espanholas dos povos indígenas, nas costas do Pacífico, no século XVI. Particularmente interessante é o relato do jesuíta Bernabe Cobo (1582?-1657) intitulado Del cómputo del tiempo; de los quipos o memoriales y modo de contar que tenían los índios peruanos.(BIBLIOTECA, t. XCII, 1964, p.14) Temos relatos bem ricos sobre as conquistas espanholas que dão muita informação sobre a matemática nas civilizações asteca, maia e inca, bem como de outras culturas andinas.

Tanto Bernabe Cobo quanto Frei Vicente do Salvador, ao mencionarem tempo e mercado, mostram grande sensibilidade no entender a natureza do conhecimento. Mas imediatamente, como não é de se estranhar, eles partem para reflexões de natureza comparativa. Ainda hoje em dia se nota essa distorção na maneira de analisar a matemática de culturas marginais, seja nas populações indígenas, seja nas marginalizadas rurais e urbanas. Curioso notar que Bernabe Cobo vê o sistema numérico do Peru associado à contagem do tempo, enquanto Frei Vicente do Salvador tem uma percepção essencialmente mercantilista dos sistemas de numeração.

Ainda hoje pesquisadores relatam comportamento e conhecimento indígenas. Destaco - livro de Mariana Kawall Leal Ferreira sobre contagem indígena. (FERREIRA, 1998) Menciono também as dissertações de Samuel Lopez Bello sobre educação matemática indígena, (BELLO, 1995) e de Chateaubriand Nunes Amancio, sobre técnicas de pescaria entre os kanhgág.(AMANCIO, 1999) A pesquisa de Daniel L. Everett é muito importante ao destacar a influência mútua no desenvolvimento de linguagem e de contagem na cultura do povo pirahã, na Amazônia. (EVERETT, 2008)

Alguns estudos de etnomatemática procuram enveredar pela história das tradições e permitem fazer algumas suposições sobre a natureza do conhecimento indígena na época da conquista. Por exemplo, resquícios de sistemas de numeração e a riqueza das figuras geométricas que intervêm na decoração são indicadores de uma organização de conhecimentos sobre quantificação, classificação, ordenação e outras categorias que caracterizam o conhecimento matemático.

\section{Conclusão}

Os cronistas eram, como ainda são, obcecados por entender o outro, por entender e explicar fatos e fenômenos. Entender implica a ação de observar, fruto de uma contemplação intelectual, como vendo um espetáculo ou participando de uma festa. É uma arte e ao mesmo tempo uma reação retórica (e em certos contextos, uma prática) de rejeição ou continência ou de aceitação e aquisição, a serviço da política, da moralidade, da filosofia, da religião, da saúde e de outros interesses. Quem procura entender está claramente consciente de sua arte, projeta suas preocupações e ideias e destaca eventos 
marcantes, mesmo que suas causas e seus determinantes subjacentes estejam abaixo do nível de compreensão dos seus contemporâneos, que não estavam conscientes, às vezes nem estavam cientes, mas que involuntariamente lidavam com suas conseqüências. Eventos, fatos e fenômenos que escapavam à observação e não foram registrados na documentação da época. Mas que fazem parte da memória cultural e das tradições dos povos.

O que podemos saber hoje em dia dessas culturas é auxiliado por estudos da etnomatemática de culturas sobreviventes. Obviamente, as pesquisas nos mostram a cultura atual, que difere da cultura original, pois foi modificada como resultado de uma dinâmica de encontros culturais. Como os comportamentos e os conhecimentos tradicionais foram gerados, organizados individual e socialmente e como foram transmitidos e difundidos é o grande desafio abordado pelo Programa Etnomatemática.

\section{Referências}

ALFONSO-GOLDFARB, A. M. Livro do Tesouro de Alexandre, trad. do original árabe de S. Jubran e A.M. Alfonso Goldfarb, Editora Vozes, São Paulo, 1999

AMANCIO, Chateaubriand Nunes. Os kanhgág da Bacia do Tibagi: um estudo etnomatemático em comunidades indígenas, Rio Claro: IGCEX/UNESP, 1999.

BELLO, Samuel Lopez. Educação matemática indígena - um estudo etnomatemático dos indios guarani-kaiová do Mato Grosso do Sul, Curitiba: Universidade Federal do Paraná, 1995.

BIBLIOTECA DE AUTORES ESPAÑOLES, Tomo XCII, Obras del P. Bernabe Cobo II, Atlas, Madrid, 1964; p.14.

EVERETT, D. L. Don't Sleep, There Are Snakes. New York: Pantheon Books, 2008.

FERREIRA, M. K. L. Madikauku. Os dez dedos das mãos: Matemática e povos indígenas no Brasil. Brasília: MEC/SEF, 1998.

SALVADOR, Frei Vicente do: História do Brasil 1500-1627. Revisão de Capistrano de Abreu, Rodolfo Garcia e Frei Venâncio Willeke. São Paulo: OFM, Edições Melhoramentos, 1965; pp. 89-90.

SERTIMA, I. van. They Came Before Columbus, New York: Random House, 1976.

VITRÚVIO. Da Arquitetura, intr. Júlio R. Katinsky, trad. Marco Aurélio Lagonegro, Hucitec, São Paulo, 1999.

WELDSHMAN N. They Came Before Columbus - a Review, Perspectives in History, vol.XVIII, 2002-2003, pp.87-90. 